\title{
Isolation, culture and identification of human adipose-derived stem cells
}

\author{
JIAN-MEI WANG, YAN GU, CAI-JUN PAN and LI-RONG YIN
}

Department of Gynaecology and Obstetrics, The Second Hospital of Tianjin Medical University, Tianjin 300211, P.R. China

Received February 11, 2015; Accepted November 7, 2016

DOI: $10.3892 /$ etm.2017.4069

\begin{abstract}
The aim of the present study was to improve methods for the isolation and identification of adipose-derived stem cells (ASCs). Human subcutaneous adipose tissue was collected during liposuction surgery, without ultrasound-assisted liposuction and other assisted techniques, and digested with $0.075 \%$ collagenase I. First (P1) and second (P2) passage ASCs were applied to the subsequent experiments. ASCs were observed under a microscope, the growth curves of the cells were assessed using a cell counting kit- 8 assay and the membrane expression of cell surface antigens, including cluster of differentiation (CD)44, CD105 and CD45, were detected by flow cytometry. In addition, ASCs were induced to differentiate into lipocytes and osteocytes. Oil red staining was applied to examine adipogenic induction, whereas alkaline phosphatase (ALP) staining was used to assess osteogenic induction. Primary ASCs adhered to the culture vessel wall after $72 \mathrm{~h}$, were fusiform in appearance at 5 days and exhibited stable growth with active proliferation. In total, $1 \times 10^{5}$ stem cells were gained per $50 \mathrm{ml}$ of lipo-aspirate. ASCs were plated in a $25 \mathrm{~cm}^{2}$ culture flask at a density of $5 \times 10^{4} / \mathrm{ml}$; the cells underwent the first logarithmic growth period after $72 \mathrm{~h}$ and grew to $90 \%$ confluence within 3 days. Flow cytometry demonstrated that the cells were highly positive for CD105 and CD44, and weakly positive for CD45; $18.6 \%$ of P1 cells and $90.7 \%$ of P2 cells were $\mathrm{CD} 44^{+} \mathrm{CD} 45^{-} \mathrm{CD} 105^{+}$. Oil red and ALP staining were positive. The results of the present study suggested that ASCs may be considered a promising cell type for tissue engineering. Furthermore, the present study established an effective method for the isolation and identification of ASCs, which reduced damage to the stem cells and simplified the identification procedure.
\end{abstract}

Correspondence to: Professor Li-Rong Yin, Department of Gynaecology and Obstetrics, The Second Hospital of Tianjin Medical University, 23 Pingjiang Road, Tianjin 300211, P.R. China E-mail: bsfanyi@163.com

Key words: adipose-derived stem cells, liposuction surgery, adipogenic induction, simplified

\section{Introduction}

Human adipose-derived stem cells (ASCs) were initially isolated from the aspirate of human fat by Zuk et al (1). ASCs are convenient to obtain, have broad sources, a long culturing time, strong breeding ability and are not associated with ethical issues. Furthermore, ASCs possess identical immunosuppressive effects to bone marrow-derived mesenchymal stem cells, along with the potential to differentiate into multiple blastophyllums, including cardiac cells. ASCs are adult stem cells that have the characteristics of mesenchymal stem cells and an extremely strong ability for external amplification, as well as the potential for multi-directional differentiation. In recent years, researchers have also shown that ASCs may have a paracrine mechanism. ASCs secrete large volumes of vascular endothelial growth factor, transforming growth factor- $\beta$, hepatocyte growth factor and other active factors to promote angiogenesis and improve ischemia when transplanted into areas of myocardial necrosis. Due to their advantages in various fields, ASCs have a strong potential for application in future stem cell treatments and are beneficial for allogenic transplantation treatments. ASCs may emerge as the ideal seed stem cells in cell transplantation and tissue engineering clinical treatments (2-5).

In accordance with the summary of worldwide experience in obtaining, isolating, cultivating and identifying ASCs, the present study has improved existing methods for these processes in order to reduce damage to and simplify the identification of ASCs.

\section{Materials and methods}

Reagents. Fetal bovine serum (FBS), type I collagenase and trypsin were obtained from Sigma-Aldrich (Merck Millipore, Darmstadt, Germany). Osteogenic and adipogenic differentiation cultivating media were purchased from Cyagen Biosciences (Santa Clara, CA, USA). Oil Red O dye and Dulbecco's Modified Eagle's Medium (DMEM)-F12 cultivating medium were obtained from Bio Teke Corporation (Beijing, China). Mouse anti-cluster of differentiation (CD)44, anti-CD105 and anti-CD45 monoclonal antibodies were purchased from Kangchen Bio-tech Corporation (Shanghai, China).

Separation and cultivation of ASCs. Conventional liposuction using negative pressure suction with abdominal distention 
was performed under aseptic conditions on five female volunteers aged between 25 and 29 years at the Department of Gynaecology and Obstetrics, The Second Hospital of Tianjin Medical University (Tianjin, China), according to a previous study (6). The present study was approved by The Second Hospital of Tianjin Medical University. The body mass indexes of the patients ranged from $25.7-29.9 \mathrm{~kg} / \mathrm{m}^{2}$. Fat aspirate (50 $\mathrm{ml} /$ patient) was obtained via the injector negative-pressure method (6), in the absence of excessive distention solution and the assistance of ultrasonic emulsification or resonance technology. Prior to the cessation of the anesthetic $(100 \mathrm{mg}$ lidocaine), the same volume of PBS $(5 \mathrm{ml})$ was administered and hemocytes in the liposuction were centrifuged at 1,200 x $g$ for $10 \mathrm{~min}$ at $37^{\circ} \mathrm{C}$. The stock solution of collagenase I was diluted to $0.075 \%$ using PBS, after which the adipose tissue was transferred into a $50 \mathrm{ml}$ centrifuge tube containing collagenase I. The tissue was shredded using a small pair of scissors, after which the tube was sealed with sealing film and centrifuged at $37^{\circ} \mathrm{C}$ and $1,200 \times \mathrm{g}$ for $30 \mathrm{~min}$. The resulting pellet was resuspended in DMEM containing $10 \%$ FBS (complete medium) with the same volume of digestive enzyme (BioTeke Corporation, Beijing, China) to terminate the collagenase-mediated digestion, after which centrifugation at $1,200 \times \mathrm{g}$ for $10 \mathrm{~min}$ was performed to subside the cells. After removal of the supernatant, the cells were sedimented by centrifugation at $1,200 \times \mathrm{g}$ for $10 \mathrm{~min}$. Complete medium that was 10 times the cell sedimentation volume was placed in a centrifuge tube. Subsequently, the cells were inoculated into a $10-\mathrm{cm}$ culture vessel at a density of $30-50 \%$, followed by the addition of complete medium to a final volume of $10 \mathrm{ml}$. After $24 \mathrm{~h}$, the medium was replaced to remove non-adherent cells; half of the medium was replaced every 2 days until the cells reached a confluency of $80-90 \%$. The offspring produced in this step were called the first passage (P1) cells and were frozen. Differentiation was induced upon reaching $80-90 \%$ confluency.

ASCs oriented differentiation into osteogenic cells. Second passage (P2) ASCs were seeded into 6-well plates at a density of $20-30 \%$, followed by the addition of osteogenic-inducing medium (HUXMD-90021; Cyagen Biosciences). The medium was replaced every 2 days during the 2 weeks of constant culture when the cells were not proliferating exponentially. After 2 weeks, the cells were removed for alkaline phosphatase staining, and the cells were visualized under a confocal microscope.

ASCs oriented differentiation into adipogenic cells. P2 ASCs were seeded into 6-well plates at a confluency of $20-30 \%$, followed by the addition of adipogenic-inducing medium (HUXMD-90031; Cyagen Biosciences). The medium was replaced every other day for 1 week, after which the cell climbing was removed for Oil Red staining, and the cells were visualized under a microscope.

Proliferation activity of ASCs and their directional differentiated cells. P2 ASCs (3,000 cells) were placed into wells containing $100 \mu \mathrm{l}$ DMEM culture medium, after which $100 \mu \mathrm{l}$ adipogenic- or osteogenic-inducing differentiation media were added to some of the wells. In addition, $10 \mu \mathrm{l}$ cell counting kit (CCK)-8 solution and $10 \mu \mathrm{l}$ cell culturing solution were added to each well. The wells without allocated cells served as the blank control. The cells were incubated for $2 \mathrm{~h}$ at $37^{\circ} \mathrm{C}$, after which the absorbance was measured at $450 \mathrm{~nm}$ using a spectrophotometer.

Identifying the surface antigens of ASCs by flow cytometry. P2 ASCs were digested with trypsin and then rinsed twice with the Stain Buffer (Merck Millipore), which had been pre-cooled at $4^{\circ} \mathrm{C}$, prior to re-suspension to adjust the cell density to $2 \times 10^{7}$ cells $/ \mathrm{ml}$. The cell suspension $\left(50 \mu \mathrm{l} ; 1 \times 10^{6}\right.$ cells $)$ was added to $1.5 \mathrm{ml}$ EP tubes, after which the cells were incubated with $1 \mu \mathrm{g}$ anti-CD44 (cat no. GD-x0297M-AF567), anti-CD45 (cat no. GD-x0297M-AF468) and anti-CD105 (cat no. GD-x0297M-AF555) antibodies (1:100 dilution) in the dark for $20 \mathrm{~min}$ at $37^{\circ} \mathrm{C}$. Subsequently, the cell suspension was centrifuged at $300 \times \mathrm{g}$ for $5 \mathrm{~min}$, followed by removal of the supernatant and resuspension of the sediment in $200 \mu \mathrm{l}$ Stain Buffer. All steps were repeated twice prior to analysis in the flow cytometer.

\section{Results}

Morphology and growth of ASCs. When observed under a microscope, a small number of the original cells had adhered to the culture vessel walls after $72 \mathrm{~h}$. In addition, on day 14, the cells were short fusiform and polygon in appearance. Over time, the morphology of the ASCs altered into a long shuttle shape that resembled fiber cells and bone marrow derived mesenchymal stem cells. Lastly, the cells merged into sheets and exhibited spiral growth upon reaching confluence. Notably, the P2 cells grew at a faster rate compared with the P1 cells (Fig. 1A and B).

Identification of multi-differentiation potential. During the 2-week incubation in osteogenic-inducing medium, the number of irregularly shaped cells increased in the experimental group and alkaline phosphatase staining was positive, indicating successful osteogenic induction of ASCs. Conversely, the control group retained in their fiber cell appearance and alkaline phosphatase staining was as negative (Fig. 1C and D).

After the 1-week incubation in adipogenic-inducing medium, lipid droplets of various sizes could be seen in the experimental group cells, and Oil Red O dye staining was positive. In contrast, the control group cells were negative for Oil Red $\mathrm{O}$ dye staining (Fig. 1E and F).

Proliferation activity of ASCs and their directional differentiation cells. Osteogenic and adipogenic inductions were performed on the P2 ASCs. ASCs cultured in DMEM were used as a control. The proliferation of the cells was assessed using the CCK- 8 assay. P2 cells cultured in DMEM proliferated at a faster rate, as compared with the P2 cells cultured in osteogenic and adipogenic induction medium (Fig. 2).

Identifying the surface antigens of ASCs with flow cytometry. Flow cytometric analysis of the surface markers on both P1 and P2 ASCs demonstrated that the percentage of CD $44^{+} \mathrm{CD} 45^{-} \mathrm{CD} 105^{+}$cell subsets was $18.6 \%$ in $\mathrm{P} 1$ and $90.7 \%$ in P2 ASCs (Fig. 3). 
A

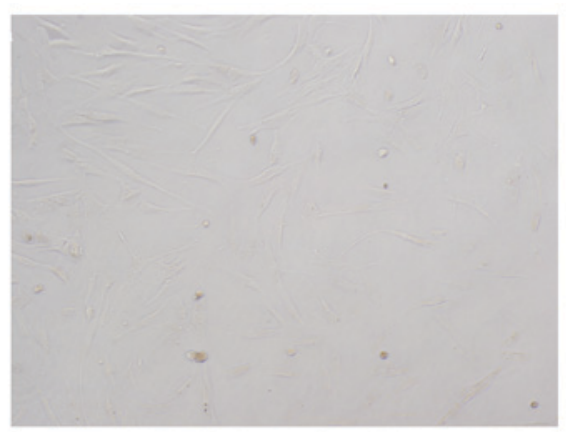

C

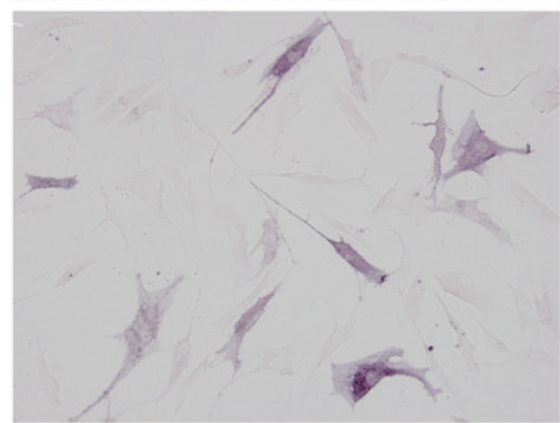

$\mathbf{E}$

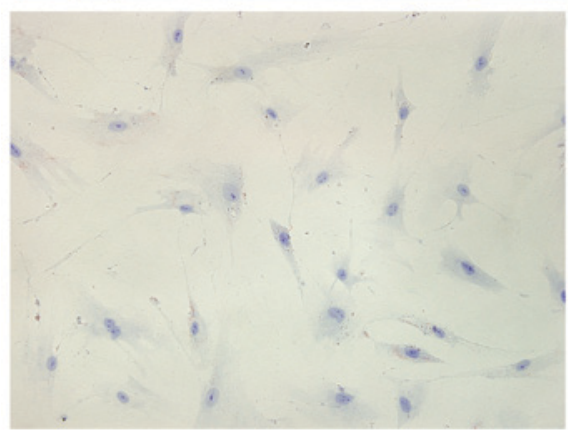

B

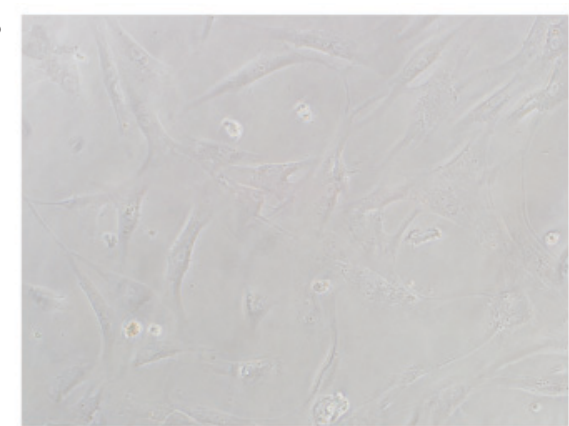

D

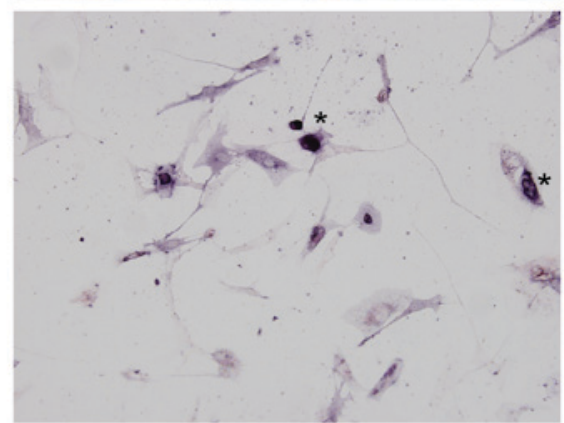

F

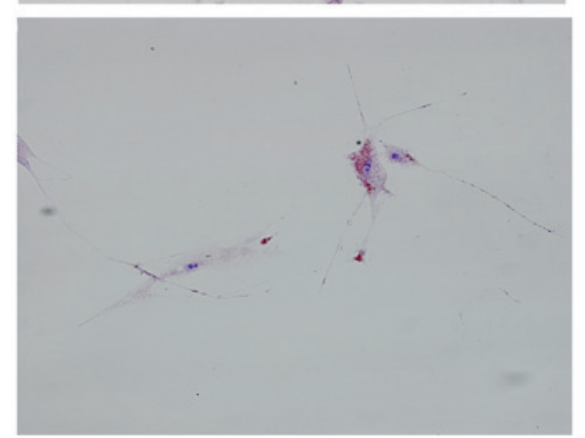

Figure 1. Morphology, growth and staining of ASCs. (A and B) The cellular morphology of P2 ASCs on day 14 was observed under an inverted microscope (A: magnification, x100; B: magnification, x200). Alkaline phosphatase staining was negative for (C) control group ASCs (magnification, x100) and positive for (D) ASCs (P2) cultured in osteogenic-inducing medium (magnification, x200; the asterisks indicate positive cells). Oil red staining was negative in (E) control group ASCs (magnification, x100) and positive in (F) ASCs cultured in adipogenic-inducing medium (magnification, x200). ASCs, adipose-derived stem cells.
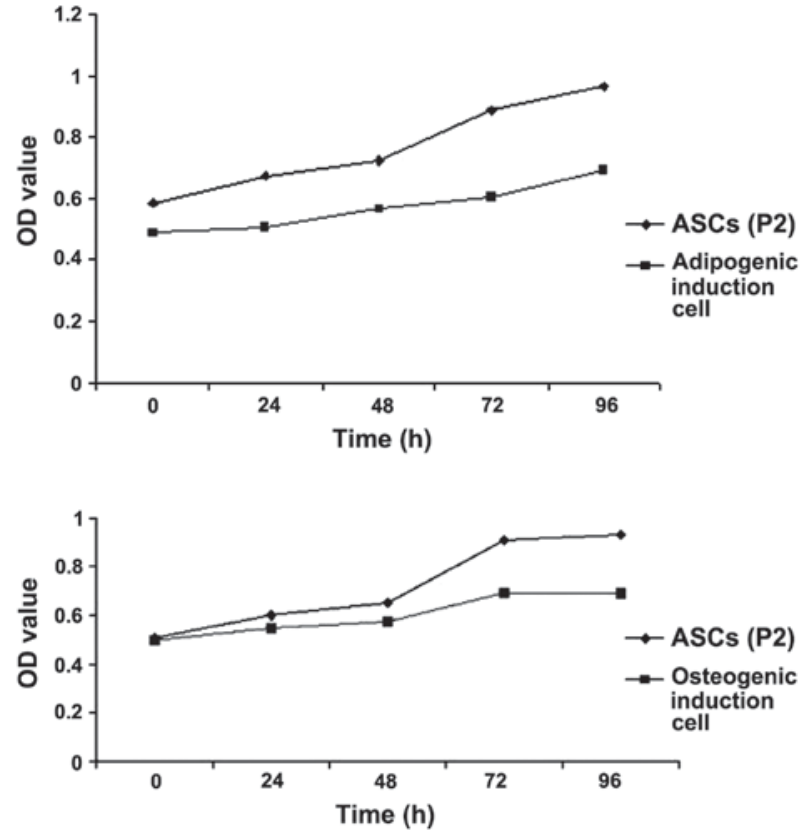

Figure 2. Comparison of the proliferative activity of ASCs and the differentiated cells. Cell proliferation was assessed using the cell counting kit- 8 method. ASCs, adipose-derived stem cells; OD, optical density.

\section{Discussion}

Adult ASCs are convenient to obtain, have broad sources, a long culturing time, strong breeding ability and are not associated with ethical issues. Furthermore, they have the potential of differentiating into multiple blastophyllums, including cardiac cells $(7,8)$, and they possess identical immunosuppressive effects to bone marrow-derived mesenchymal stem cells (9-12), making them beneficial for allogenic transplantation treatments. Therefore, ASCs may emerge as the ideal seed stem cells in future cell transplantation and tissue engineering clinical practices.

A set of highly practical methods for extracting, culturing and identifying ASCs have been improved in this study. First, when selecting the donor tissues, the search was limited to young female volunteers aged between 25 and 30 years who had BMIs of $25-30 \mathrm{~kg} / \mathrm{m}^{2}$, in order to minimize the confounding effects of underlying conditions. It has previously been reported that BMI and ASC yield are negatively correlated $(r=-0.44, \mathrm{P}<0.05)$, and that age does not influence ASC yield ( $r=-0.17, \mathrm{P}=0.27$ ) (13). However, Yu, et al (14) hypothesized that there are positive correlations among BMI, age and ASC yield. Secondly, liposuction was selected as the 
A

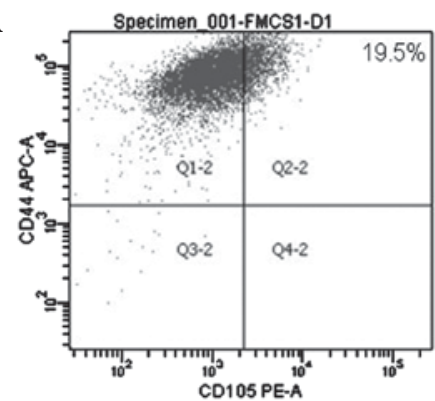

$\mathbf{B}$

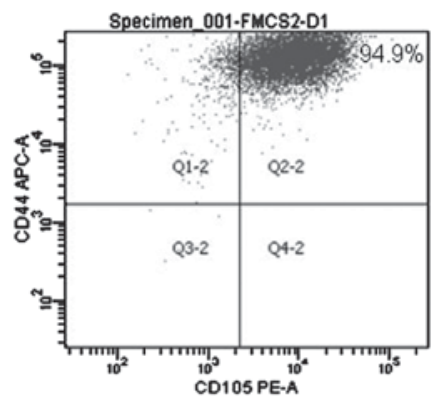

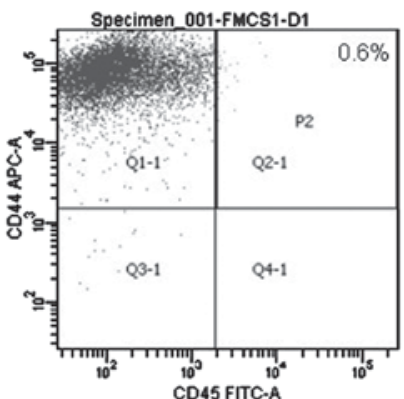
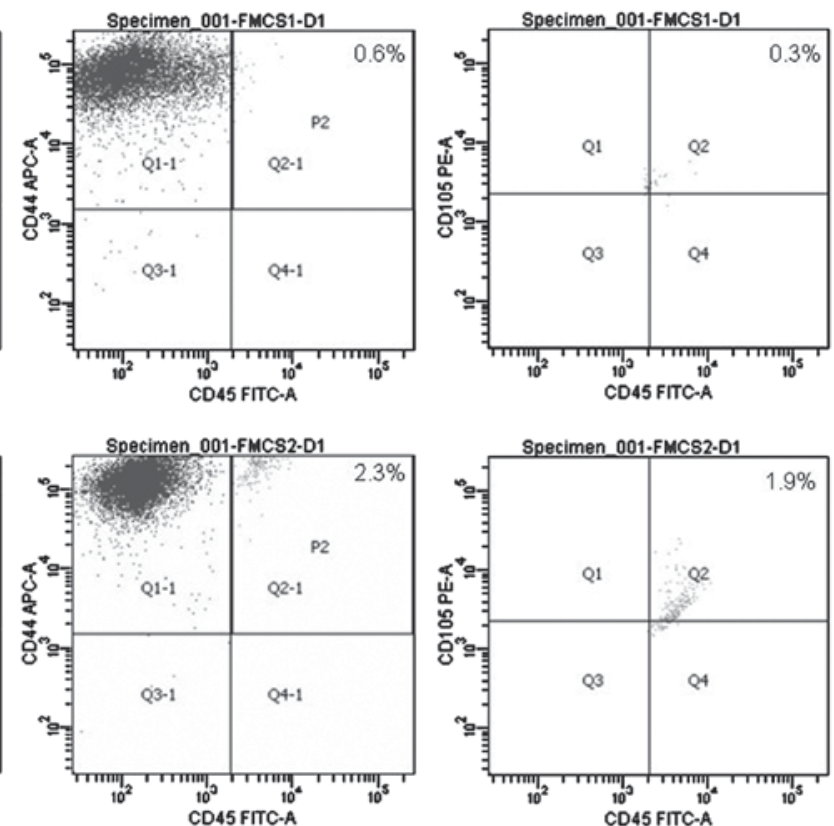

Figure 3. Identifying the surface antigens of ASCs using flow cytometry. (A) $\mathrm{CD} 44^{+} \mathrm{CD} 45^{-} \mathrm{CD} 105^{+}$subset in $\mathrm{P} 1 \mathrm{ASCs}$ was $18.6 \%$. (B) $\mathrm{CD} 44^{+} \mathrm{CD} 45^{-} \mathrm{CD} 105^{+}$ subset in P2 ASCs was 90.7\%. ASCs, adipose-derived stem cells; CD, cluster of differentiation; APC, allophycocyanin; PE, phycoerythrin; FITC, fluorescein isothiocyanate.

method to obtain adipose tissues, as the amount of subcutaneous fat obtained by conventional surgeries is usually limited and a lot of time is spent on repeated shearing during the separation process (15). The present study adopted the method used by Panfilov et al (6), in which a fixed amount of fat is initially extracted using a 50-ml injector under negative pressure and in the absence of external ultrasonic emulsification technology (16), resonance technology or the excessive expansion solution method in order to prevent damage to the adipose cells. Therefore, in comparison with existing surgical and liposuction methods involving additional techniques, the method used in the present study allowed time to be saved when obtaining fat tissues, as well as the number of living cells to be maximized, thereby improving the acquisition rate of ASCs.

During the separation phase of the ASCs, low-concentration $(0.075 \%)$ collagenase was used to separate the cells. Although this method increased the digesting time, as compared with the combined enzyme digestion method and high-concentration trypsin solution method chosen by previous studies $(17,18)$, it avoided excessive damage to the cells. In addition, the fluid replacement method was selected in order to remove red blood cells from the suspension and thereby avoid the use of the conventional $\mathrm{NH}_{4} \mathrm{CI}$ method (19), which typically harms the cells; this also increased the number and activity of the ASCs. Based on our calculations, $1 \times 10^{5}$ ASCs was acquired from every $50 \mathrm{ml}$ of fat aspirate. Furthermore, it was discovered that the breeding ability of the ASCs was increased; by observing two $25-\mathrm{cm}$ culturing vessels initially containing $\sim 5 \times 10^{4}$ cells, a logarithmic growth period was observed as commencing after $72 \mathrm{~h}$, and the time needed for fusion was $\sim 7$ days, which was similar to a previous study (20).

Taking into consideration the current lack of identification methods specific for ASCs, the present study referred to the newest joint declaration of the International Federation for Adipose Therapeutics and Science and the International Society for Cellular Therapy (21), which describes the conformation and simplification of the identification of ASCs as its fundamental purpose. This declaration suggests that ASC identification should involve comprehensive identification involving assessment of tissue origin, cellular morphology, surface markers and their multi-differentiation potential (21). Particularly important is selecting and identifying the surface markers of ASCs, as the surface markers of stem cells transform over successive generations of cells (22). Therefore, the present study selected three comparably stable markers according to the joint declaration (21), along with a number of global experimental reports $(23,24)$. Among them, CD45 has commonly been used as a surface marker for hemopoietic stem cells; thus, the persistent negative result in the present study helped to rule out this type of stem cells (24). CD105 is a marker of mesenchymal stem cells, while CD44 is a stable marker for ASCs; both are highly expressed in ASCs and, therefore, the identification of ASCs based on surface markers was simplified, while the cost of and time spent on screening for markers was reduced (25). Furthermore, desmocytes, which are similar to ASCs, could be effectively distinguished through the multi-differentiation ability of ASCs.

By using P1 and P2 ASCs in the experiments, the results suggested that a low positive rate of P1 ASCs should be related to adherent cells and contamination with other cells. In accordance to relevant documents and experimental reports, ASCs show signs of aging after being cultured for 10 generations $(3,4)$. On the other hand, the present study has demonstrated that P2 stem cells show satisfying purity and breeding activity, and, hence, P2 cells have been selected to be stored for future use.

In conclusion, the present study has improved methods for the isolation, cultivation and identification of ASCs, thereby 
reducing damage to ASCs, simplifying their identification and increasing the ASC yield from adipose aspirate. This has allowed the establishment of mature and stable stem cell sources for future research.

\section{References}

1. Zuk PA, Zhu M, Mizuno H, Huang J, Futrell JW, Katz AJ, Benhaim P, Lorenz HP and Hedrick MH: Multilineage cells from human adipose tissue: Implications for cell-based therapies. Tissue Eng 7: 211-228, 2001.

2. LapPar DJ, Kron IL and Yang Z: Stem cell therapy for ischemic heart disease: Where are we? Curr Opin Organ Transplant 14 79-84, 2009.

3. Yang Z, Hao J and Hu ZM: MicroRNA expression profiles in human adipose-derived stem cells during chondrogenic differentiation. Int J Mol Med 35: 579-586, 2015.

4. Laflamme MA and Murry CE: Heart regeneration. Nature 473: 326-335, 2011.

5. Singh D, Nayak V and Kumar A: Proliferation of myoblast skeletal cells on three-dimensional supermacroporous cryogels. Int J Biol Sci 6: 371-381, 2010

6. Panfilov IA, de Jong R, Takashima S and Duckers HJ: Clinical study using adipose-derived mesenchymal-like stem cells in acute myocardial infarction and heart failure. Methods Mol Biol 1036: 207-212, 2013.

7. Miyahara Y, Nagaya N, Kataoka M, Yanagawa B, Tanaka K, Hao H, Ishino K, Ishida H, Shimizu T, Kangawa K, et al: Monolayered mesenchymal stem cells repair scarred myocardium after myocardial infarction. Nat Med 12: 459-465, 2006.

8. Planat-Bénard V, Menard C, André M, Puceat M, Perez A, Garcia-Verdugo JM, Pénicaud L and Casteilla L: Spontaneous cardiomyocyte differentiation from adipose tissue stromal cells. Circ Res 94: 223-229, 2004.

9. McIntosh K, Zvonic S, Garrett S, Mitchell JB, Floyd ZE, Hammill L, Kloster A, Di Halvorsen Y, Ting JP, Storms RW, et al: The immunogenicity of human adipose-derived cells: Temporal changes in vitro. Stem Cells 24: 1246-1253, 2006.

10. Puissant B, Barreau C, Bourin P, Clavel C, Corre J, Bousquet C, Taureau C, Cousin B, Abbal M, Laharrague $\mathrm{P}$, et al: Immunomodulatory effect of human adipose tissue-derived adult stem cells: Comparison with bone marrow mesenchymal stem cells. Br J Haematol 129: 118-129, 2005.

11. Han ZM, Huang HM and Wang FF: Brain-derived neurotrophic factor gene-modified bone marrow mesenchymal stem cells. Exp Ther Med 9: 519-522, 2015.

12. DI $C$ and Zhao Y: Multiple drug resistance due to resistance to stem cells and stem cell treatment progress in cancer (Review). Exp Ther Med 9: 289-293, 2015.

13. Aust L, Devlin B, Foster SJ, Halvorsen YD, Hicok K, du Laney T, Sen A, Willingmyre GD and Gimble JM: Yield of human adipose-derived adult stem cells from liposuction aspirates. Cytotherapy 6: 7-14, 2004.
14. Yu G, Wu X, Dietrich MA, Polk P, Scott LK, Ptitsyn AA and Gimble JM: Yield and characterization of subcutaneous human adipose-derived stem cells by flow cytometric and adipogenic mRNA analyzes. Cytotherapy 12: 538-546, 2010.

15. Jin J, Jeong SI, Shin YM, Lim KS, Shin Hs, Lee YM, Koh HC and Kim KS: Transplantation of mesenchymal stem cells within a poly(lactide-co-epsilon-caprolactone) scaffold improves cardiac function in a rat myocardial infarction model. Eur J Heart Fail 11: 147-153, 2009.

16. Oedayrajsingh-Varma MJ, van Ham SM, Knippenberg M, Helder MN, Klein-Nulend J, Schouten TE, Ritt MJ and van Milligen FJ: Adipose tissue-derived mesenchymal stem cell yield and growth characteristics are affected by the tissue-harvesting procedure. Cytotherapy 8: 166-177, 2006.

17. Kang S, Han J, Song SY, Kim WS, Shin S, Kim JH, Ahn H, Jeong JH, Hwang SJ and Sung JH: Lysophosphatidic acid increases the proliferation and migration of adipose-derived stem cells via the generation of reactive oxygen species. Mol Med Rep 12: 145-149, 2015

18. Pan F, Liao N, Zheng Y, Wang Y, Gao Y, Wang S, Jiang Y and Liu X: Intrahepatic transplantation of adipose-derived stem cells attenuates the progression of non-alcoholic fatty liver disease in rats. Mol Med Rep 26: 3725-3733, 2015.

19. Lee RH, Kim B, Choi I, Kim H, Choi HS, Suh K, Bae YC and Jung JS: Characterization and expression analysis of mesenchymal stem cells from human bone marrow and adipose tissue. Cell Physiol Biochem 14: 311-324, 2004.

20. Boquest AC, Shahdadfar A, Brinehmann JE and Collas P: Isolation of stromal stem cells from human adipose tissue. Methods Mol Biol 325: 35-46, 2006.

21. Bourin P, Bunnell BA, Casteilla L, Dominici M, Katz AJ, March KL, Redl H, Rubin JP, Yoshimura K and Gimble JM: Stromal cells from the adipose tissue-derived stromal vascular fraction and culture expanded adipose tissue-derived stromal/stem cells: A joint statement of the international federation for adipose therapeutics and science (IFATS) and the international society for cellular therapy (ISCT). Cytotherapy 15: 641-648, 2013.

22. Park HS, Kim JH, Sun BK, Song SU, Suh W and Sung JH: Hypoxia induces glucose uptake and metabolism of adipose-derived stem cells. Mol Med Rep 14: 4706-4714, 2016.

23. Gimble JM, Katz AJ and Bunnell BA: Adipose-derived stem cells for regenerative medicine. Circ Res 100: 1249-1260, 2007.

24. Zuk PA, Zhu M, Ashjian P, De Ugarte DA, Huang JI, Mizuno H, Alfonso ZC, Fraser JK, Benhaim P and Hedrick MH: Human adipose tissue is a source of multipotent stem cells. Mol Biol Cell 13: 4279-4295, 2002.

25. Fu X, Tong Z, Li Q, Niu Q, Zhang Z, Tong X, Tong L and Zhang X: Induction of adipose-derived stem cells into Schwann-like cells and observation of Schwann-like cell proliferation. Mol Med Rep 14: 1187-1193, 2016. 